\title{
O MANEJO FLORESTAL SUSTENTÁVEL DA CAATINGA
}

\author{
SUSTAINABLE FOREST MANAGEMENT OF CAATINGA
}

\author{
Adriele Gomes da Silva ${ }^{1}$ \\ Larissa Oliveira Vilar ${ }^{2}$ \\ Viviane Oliveira Vilar ${ }^{3}$ \\ Fernando Pinto Coelho 4 \\ Nayara Rithelly dos Santos Acioli ${ }^{5}$ \\ Ramon Brilhante Gonçalves Araújo Ramos ${ }^{6}$ \\ Jefferson Gomes Moreira ${ }^{7}$ \\ Thiago Rocha Diares 8 \\ Danielly Ferreira da Silva ${ }^{9}$ \\ Mayra Santos da Cruz ${ }^{10}$ \\ Ricardo Gonzaga de Moura ${ }^{11}$
}

RESUMO: Sabendo da importância e das peculiaridades da caatinga traremos por meio desse artigo esclarecimentos e informações que conscientizem os pequenos e médios produtores do quanto a ação antrópica tem afetado negativamente o bioma, colocando inclusive algumas áreas da região em risco de desertificação. Para tanto, foi utilizado o método de pesquisa exploratória pois a atual situação enfrentada pelo país impossibilita uma pesquisa de campo, mas vale ressaltar que esse artigo não foi

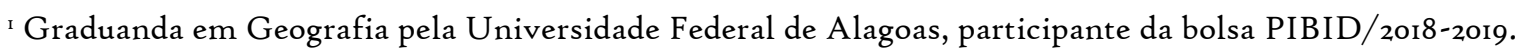

${ }^{2}$ Graduanda em Geografia pela Universidade Federal de Alagoas. E-mail: larissavilaro4o@gmail.com.

${ }^{3}$ Graduanda em Geografia pela Universidade Federal de Alagoas.

4 Perito em Análise Ambiental pela Corregedoria do Tribunal de Justiça do Estado de Alagoas (2019). Doutor em Tecnologias Energéticas e Nucleares pela Universidade Federal de Pernambuco - UFPE (2018), área de concentração em energias renováveis e linha de pesquisa em meio ambiente e energia da biomassa. Prof. Orientador do Programa Federal Residência Pedagógica (2018). Consultor Ad Hoc do Ministério de Educação e Cultura - MEC (2014). Líder do Grupo de Pesquisa do CNPq. Núcleo de Produção de Energia do Semiárido Alagoano - NUPRES - AL (2013). Prof. da área de Hidrografia com especialização em Climatologia e Avaliação de Impactos Ambientais pela Universidade Federal de Alagoas - Campus do Sertão - UFAL (2OII). Mestre em Recursos Hídricos e Saneamento - Universidade Federal de Alagoas - UFAL (2008). Master Business Administration (MBA) em gestão empresarial - Fundação Getúlio Vargas - FGV (2002). Graduado em Geografia - Licenciatura Plena - Universidade Federal de Alagoas (1999).

5 Graduanda em geografia pela Universidade Federal de Alagoas.

${ }^{6}$ Graduando em Geografia pela Universidade Federal de Alagoas, participante da bolsa PIBID/2018-2019.

7 Graduando em Geografia pela Universidade Federal de Alagoas.

${ }^{8}$ Graduando em geografia pela Universidade Federal de Alagoas- UFAL. Técnico em Agropecuária pelo instituto federal de ciências e tecnologia de Alagoas- IFAL Integrante da comissão Municipal de Geografia e estatística -CMGE do instituto brasileiro de geografia e estatística- IBGE. E-mail: thiagodiares2015@gmail.com.

9 Graduanda em Geografia pela Universidade Federal de Alagoas- UFAL. E-mail: danny.97ferreira@gmail.com.

ro Graduanda em Geografia pela Universidade Federal de Alagoas.

II Graduando pela Universidade Federal de Alagoas, Residente Pedagógico pela CAPES, vinculado ao projeto/subprojeto UFAL - GEOGRAFIA no período de Novembro de 2018 a Janeiro de 202o. Técnico em segurança do trabalho pela Escola de formação Técnica Carneiro do Vale, durante o período de 2013 a 2015. 
prejudicado por tal situação visto que o tipo de pesquisa utilizada e seus parâmetros técnicos de estudo bibliográfico nos garantiu ricas fontes de informações. Dessa forma, foi possível conseguir dados que comprovam a degradação constante que a caatinga vem sofrendo ao longo dos anos e mostra a problematização que a interferência inconsequente do homem traz, colocando em risco o bioma. Portanto, fazer essa parcela específica da população saber sobre o que é e quais os benefícios do uso correto do solo e da vegetação por meio da conscientização e do manejo sustentável do bioma é importante e indispensável para garantir a preservação desse bioma exclusivamente brasileiro.

Palavras-Chave: Manejo Florestal, Caatinga, Manejo sustentável.

ABSTRACT: Biome, putting even some areas of the region at risk of desertification. To this end, the exploratory research method was used because the current situation faced by the country makes field research impossible, but it is worth mentioning that this article was not affected by such situation since the type of research used and its technical parameters of bibliographic study in secured rich sources of information. In this way, it was possible to obtain data that prove the constant degradation that the caatinga has suffered over the years and shows the problematization that the inconsequential interference of man brings, putting the biome at risk. Therefore, making this specific portion of the population know about what and what are the benefits of the correct use of soil and vegetation through awareness and sustainable management of the biome is important and indispensable to guarantee the preservation of this exclusively Brazilian biome.

Keyword: Forest management, Caatinga, Sustainable management.

\section{INTRODUÇÃO}

O Brasil tem um longo histórico de desmatamento em todos os biomas brasileiros, assim perdendo grande parte da sua biodiversidade, entre os biomas a Caatinga é o bioma que menos tem áreas preservadas, em grande parte da exploração dos recursos da Caatinga não é feita de maneira sustentável por tanto é de suma importância analisar formas de manejo sustentável, para que possa ser repassado para aos habitantes da região, onde por sua vez utiliza os recursos florestais do bioma. A caatinga é um bioma que predomina no Sertão do Nordeste, há outras regiões no mundo com características semelhantes, mas a caatinga é um bioma exclusivo do Brasil, o nome Caatinga significa "mata branca" em tupi-guarani, em razão da estação da seca onde a maioria das plantas perdem suas folhas, prevalecendo à paisagem clara do tronco das árvores. O bioma ocupa cerca de $844.453 \mathrm{~km}^{2}$ (IBGE, 20I4), representando $70 \%$ da área da região Nordeste e presente em 9,9\% do território brasileiro. 
O bioma estende-se através dos estados do Ceará, Paraíba, Pernambuco, Alagoas, Bahia, Piauí, Sergipe, Maranhão, Rio Grande do Norte e a faixa do norte de Minas Gerais; faz limite com mais três biomas do Brasil: a Amazônia, a Mata Atlântica e o Cerrado.

O clima predominante na região da Caatinga é o tropical semiárido, um clima com chuvas mal distribuídas e escassas, se concentrando basicamente em uma estação. $\mathrm{Na}$ vegetação da caatinga há uma grande diversidade, parte dela endêmicas, a apresentação em fisionomias da vegetação local se distingue em arbórea, arbustiva e herbácea, o solo do bioma é composto em variação de solos rasos e profundos assim podendo ter uma vegetação variada, o fato de parte do seu solo ser raso e pouco permeável e o clima ser semiárido resulta no surgimento de uma vegetação adaptada à escassez de água, ou seja, uma vegetação xerófila, assim como a flora, a fauna é diversificada composta por uma parte endêmica, $\mathrm{A}$ rede hidrográfica do bioma é marcada pela presença de rios intermitentes, exceto os principais rios, sendo eles o Rio São Francisco e o Rio Parnaíba.

De acordo com o INPE (2015), Instituto Nacional de Pesquisas Espaciais, O grupo de Geoprocessamento do Centro Regional do Nordeste (CRN) do Instituto Nacional de Pesquisas Espaciais, apresentou resultados do monitoramento por satélite da Caatinga, uma

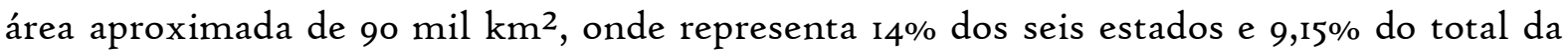
caatinga, onde revelaram 40\% da Caatinga preservada, 45\% de Caatinga degradada, 7,2\% de solo exposto, 6,5 de lavoura e o,7\% de corpos d'água.

Ainda de acordo com o INPE (2016), com a atualização do mapeamento e monitoramento sobre uma parte da área da Caatinga, sendo um avanço de $14 \%$ da área monitorada passa a ser $16 \%$ da área onde resulta que $40 \%$ da área da Caatinga se encontra degradada, $42 \%$ preservada, $8 \%$ do solo exposto, $8 \%$ utilizado para cultivo e o,8\% de corpos de água.

$\mathrm{Na}$ região são usados grandes números de espécies da fauna e flora nas atividades do sertanejo, como por exemplo para obtenção de carvão mineral, desmatamento para a expansão de pastagem e agricultura onde está associada a queimada para a preparação do solo, por tanto como citado anteriormente é de suma importância o estudo e compartilhamento de informações sobre o manejo florestal com os habitantes da região, para que o bioma Caatinga seja preservado.

Tendo em vista a importância e as peculiaridades desse bioma, esse artigo busca trazer informações e sugestões sobre como é possível viver harmonicamente com a natureza 
de modo que a interferência antrópica não prejudique de forma exagerada tanto o bioma quanto sua fauna.

\section{OBJETIVO GERAL}

Analisar o desmatamento detectado no bioma caatinga para que possam ser analisadas as formas de manejo sustentável e assim obter sua preservação com a utilização sustentável dos recursos florestais.

\section{I Objetivo específico}

- Analisar as características e a importância do bioma;

- Verificar como a ação do homem ameaça a caatinga;

- Discutir sobre o que é o manejo sustentável e a sua importância na preservação da caatinga;

- Demonstrar como usar o bioma caatinga de forma sustentável;

\section{METODOLOGIA}

Tendo em vista o conteúdo abordado até aqui nesta obra e a intencionalidade sobre o esclarecimento da temática referida, caracteriza-se, dessa maneira, a utilização da pesquisa exploratória, onde, segundo Antônio Carlos Gil (1987) As pesquisas explanatórias possuem como objetivo a intenção de esclarecer e alterar conceitos e ideias e com isso formular problemas mais precisos ou formular hipóteses que possam ser utilizadas em pesquisas de estudos futuros.

Sobre os parâmetros técnicos da pesquisa, será utilizado o estudo bibliográfico, onde pode-se conceituar, segundo Marconi e Lakatos (2003), o alcance da pesquisa bibliográfica, em toda bibliografia pública relacionada à temática estudada, utilizando livros, monografias, artigos de periódicos entre outros meios de pesquisa.

Para que se tivesse o alcance desta pesquisa bibliográfica foi utilizado autores como, GIL, GARRIDO, FILHA, GOMES e também RIEGELHAUPT. Além de utilizar também o site do IBGE para se colher dados para o desenvolvimento do artigo.

Através disto foi possível analisar as características e a importância do bioma, abordando questões para conscientização e também aspectos sobre as peculiaridades da vegetação da Caatinga e a sua importância para o clima e região. 
No primeiro momento, será abordado questões sobre a importância da vegetação da caatinga para a reprodução de vida das pessoas e suas criações, depois será apresentado as ações do homem neste bioma; aqui traremos quais as principais ações do homem que impactam negativamente o bioma, apresentaremos dados que mostram a crescente degradação da caatinga e o risco de desertificação do nordeste.

A pós isto, será feito um questionamento sobre o que é o manejo sustentável e a sua importância na preservação da caatinga; depois disto traremos as sugestões de soluções para as problematizações, apresentando o conceito de manejo sustentável, sua importância para a garantia da preservação da caatinga e por fim, orientação sobre como o manejo sustentável deve ser colocado em prática.

E por fim, será discutido como usar o bioma caatinga de forma sustentável; trazendo orientações sobre como através do manejo sustentável é possível fazer um uso sustentável do bioma de modo que não prejudique a saúde da população

\section{O QUE É MANEJO FLORESTAL SUSTENTÁVEL}

A retirada dos recursos naturais da natureza é um processo constante. No qual se necessita para a produção das mais variadas especiarias, e com isso, a obtenção de lucro por meio do comércio.

Mas como é de senso comum, nada no meio natural é infinito, tudo tem uma quantidade limitada disponível na natureza, sendo assim, a sua retirada de forma extensiva pode prejudicar diversos elementos e fatores na natureza.

Assim acontece no extrativismo, a retirada desses recursos pode acarretar consequências que atinjam a produtividade do solo, causando danos que podem ser irreparáveis.

A economia necessita desses recursos, é por meio delas que são formados os produtos a serem vendidos, a utilização como combustíveis, criação de móveis e dentre outros. Faz com que a economia continue a gerar lucros, lucros geram mais produtos, há a expansão do comércio que geram empregos, e isso sucessivamente em uma cadeia de eventos.

Mas é necessário parar e refletir nas consequências danosas que podem acarretar. 
A perda da biodiversidade, o desaparecimento de espécies nativas, e consequentemente a impossibilidade de gerar qualquer renda, seja para o comércio ou sustento familiar.

O manejo florestal proporciona uma reflexão, trazendo a possibilidade de pensar em economia atrelada aos lucros que possam trazer, sem retirar a sustentabilidade e preservação do meio ambiente.

Confirmando o pensamento anterior:

\begin{abstract}
“Manejo Florestal Sustentável é a administração da floresta para obtenção de benefícios econômicos, sociais e ambientais, respeitando-se os mecanismos de sustentação do ecossistema objeto do manejo e considerando-se, cumulativa ou alternativamente, a utilização de múltiplas espécies madeireiras, de múltiplos produtos e subprodutos não-madeireiros, bem como a utilização de outros bens e serviços florestais.”(MATA NATIVA, 2019)
\end{abstract}

O manejo florestal possui essa visão que busca equilibrar a economia e sustentabilidade, mas é necessário observar alguns aspectos importantes.

O manejo florestal irá ter alguns empecilhos no seu desenvolvimento: um será a necessidade de pesquisas para melhor manejar o solo, e as espécies do local; e outra, é a necessidade de um alto investimento por parte das empresas que extraem os recursos naturais, e unido a falta de interesse dos madeireiros nesse investimento (FILHA, 200I, p.92).

Em segundo momento o autor (GOMES, et al, 2013) vai apresentar uma pesquisa no qual o manejo florestal foi aplicado em assentamentos no município de Serra Talhada, localizada em Pernambuco, no qual se obtiveram resultados observando sua produção entre maio de 2011 a abril de 20I2, e em sua conclusão de pesquisa foi mostrado que tiveram saldos positivos comparando a produção com o manejo florestal em relação a produção sem manejo florestal, e sua importância em meio a agricultura de subsistência

Citando mais uma vez o autor:

No manejo florestal, no entanto, constatou-se saldo positivo em todas as épocas do ano, demonstrando que a atividade florestal sustentável é fundamental no complemento da renda familiar dos assentados." (GOMES, et al, 2013, p.I)

Dessa forma o objetivo em mostrar todos esses pontos e exemplos vem da necessidade de apresentar de forma resumida e introdutória o que é o manejo florestal, pontos positivos e negativos, os empecilhos para se fazer, e um exemplo de aplicação prática. 


\section{O USO INADEQUADO DOS RECURSOS FLORESTAIS DA CAATINGA}

Sabe-se que dentre os biomas brasileiros a caatinga vem a ser de fato o bioma mais valorizado e mal conhecido, e isto é algo que se deve analisar. Existe portanto uma crença perante este Bioma, ( considerado " um bioma seco e sem vida”), não se pode ser aceita, já que o bioma é riquíssimo, por mais que seja afetado por secas extremas e períodos de estiagem .

A caatinga é de fato crucial para a sobrevivência do homem nordestino, isto porque a floresta vem sendo utilizada desde os tempos remotos, na maioria das vezes de modo intensivo e de maneira inadequada para as construções rurais como as cercas, currais e telhados. O uso inadequado dos recursos florestais da Caatinga, vêm ocasionando a destruição da biodiversidade, e a perda da qualidade de vida das populações rurais, já que o Bioma tem um papel fundamental na vida do sertanejo fornecendo madeireiros e nãomadeireiros, servindo também alimentos para a criação de animais, como por exemplo na alimentação do gado no período de seca são alimentados com mandacaru que é rico em água.

Um dos problemas que afetam portanto a Caatinga é a monocultura extensiva, pois para este fim é necessário que a vegetação nativa seja retirada para que dê espaço ao plantio intensivo e extensivo, e para se fazer a "limpeza" dessa área geralmente se usa a técnica de queimadas, o que é um grande perigo principalmente se levado em consideração o tipo do clima que prevalece no nordeste e as características da vegetação. Infelizmente com a monocultura e outros tipos de atividade, o solo tem sofrido muito com estas grandes queimadas, causando assim uma degradação ainda maior no bioma, e correndo o risco de ser desertificado, devido ao desmatamento acelerado e retirada da vegetação, causando o desaparecimento de espécies endêmicas e da vegetação nativa.

Outro processo que tem prejudicado o bioma, é a caça predatória, por conta do tráfico de animais e a perda do habitat devido ao desmatamento, levando assim com que a rica biodiversidade da caatinga venha a estar em um dos mais graves estágios de vulnerabilidade. A falta portanto da prevenção, da educação e da fiscalização, vem prejudicando assim a sobrevivência da fauna silvestre. 
Desmatada e assim alterada pela ação do homem, a caatinga corre sim o risco de desaparecer, então é necessário que haja uma reeducação e fiscalização sobre este bioma essencial e riquíssimo para o povo nordestino.

\section{O USO SUSTENTÁVEL E A CONSERVAÇÃO DE RECURSOS FLORESTAIS DO BIOMA CAATINGA}

O uso sustentável de recursos florestais da Caatinga na região do Nordeste do Brasil passa por pelo menos duas questões fundamentais, segundo o Ministério do meio ambiente. A primeira questão é sobre a importância para a manutenção da economia regional, sendo ela para geração de energia, usando a biomassas ${ }^{12}$ como a lenha, que representa na segunda fonte de energia da região, ou para a comercialização de produtos florestais sejam eles madeireiros ou não pelas famílias da região e comunidades, como também para o fornecimento de forragem para o gado.

A produção florestal não-madeireira é alternativa econômica de parcela considerável da população rural que habita o Semiárido, principalmente entre mulheres, chegando a ser, em alguns casos, a principal atividade da família. Entretanto, essas atividades, realizadas sem o manejo adequado, contribuem para o processo de degradação da Caatinga, potencializado pelo permanente uso do fogo.( Ministério do meio ambiente, 2010)

A segunda questão que o ministério do meio ambiente também aborda é a informação gerada, organizada e abordada sobre o uso sustentável desses recursos florestais.

Considerando a importância da Caatinga, a informação existente ainda é escassa e pouco acessível aos mais diferentes públicos, desde os formuladores de políticas públicas até o pequeno produtor rural que tem, no recurso florestal, uma fonte alternativa de renda.É importante deixar claro que as informações disponíveis sobre o manejo florestal (...) para uma possibilidade real de utilização sustentável desses recursos, sem perda representativa de biodiversidade e da capacidade produtiva. (Ministério do meio ambiente, 2010)

A questão da sustentabilidade, por exemplo, para estes recursos florestais é fundamental visto que, com o mesmo se tem um desenvolvimento responsável de uma determinada região ou país. O mais importante é entender que é possível sim ter um manejo sustentável dos recursos florestais da caatinga, pois estes recursos têm uma grande potencialidade para ser explorado ampliando assim o seu valor e contribuição para o desenvolvimento econômico do Nordeste, melhorando assim a qualidade de vida de uma população sem prejuízo ao meio ambiente.

\footnotetext{
${ }^{12}$ Cerca de $25 \%$ da energia consumida pelos setores industrial e comercial da Região Nordeste tem origem na biomassa florestal, gerando cerca de 900 mil empregos diretos e indiretos.
} 
A Caatinga é uma das florestas secas com melhores condições para se inserir no futuro mercado mundial de energéticos florestais por vários motivos, entre eles: - o bioma está localizado muito próximo do Atlântico Central, a curtas distâncias dos maiores pólos mundiais consumidores de energéticos; • a região onde ocorre a Caatinga tem densidade populacional relativamente alta e boa infra-estrutura viária, portuária e de comunicações; • a sustentabilidade da produção está bem demonstrada e seus impactos ambientais são mínimos; • IO\% da área poderia estar disponível para manejo, podendo fornecer uma produção sustentável três a quatro vezes maior que a demanda atual, oferecendo assim um superávit considerável.(Riegelhaupt,2010, p.354)

Segundo Riegelhaupt, quando se considera a potencialidade do manejo florestal do Bioma Caatinga, é necessário diferenciar determinados aspectos como; o potencial biótico do recurso para produzir sustentavelmente madeiras e outros produtos e serviços florestais e o potencial de mercado que é entendido como a capacidade de fornecer recursos.

E por mais que seja uma das florestas mais importantes do mundo pela sua extensão, ainda assim tem recebido pouca atenção, por estar localizada, por exemplo, em áreas subdesenvolvidas e com pouca população.

\section{DISCUSSÕES E RESULTADOS}

A caatinga é um bioma importantíssimo para o desenvolvimento da fauna nativa por apresentar características específicas da região tropical semi-árido com pouca precipitação ao longo do ano e altas temperaturas, e por isso apresenta uma flora diferenciada das demais regiões, com plantas adaptadas à escassez de chuva. Mesmo apresentando uma rica biodiversidade, a caatinga ainda é um bioma onde pouco se conhece sobre, por ser pouco estudado esse bioma acaba se tornando vulnerável ao desmatamento, pois apresenta um grande potencial econômico por meio de seus recursos naturais, como potencial madeireiro, potencial sorrateiro, frutífero e medicinal, que seriam importantes aliados deste homem, se usados de forma sustentável. No entanto, apesar de apresentar tamanha riqueza natural, é um bioma que necessita de um cuidado para que não venha virar um deserto, “(...)devemos reconhecer que a Caatinga ainda carece de marcos regulatórios, ações e investimentos na sua conservação e uso sustentável.” (MMA)

A preservação das espécies endêmicas é de total relevância " Cerca de $23 \%$ do total de espécies conhecidas das FATSS (Florestas e Arbustais Tropicais Sazonalmente Secos) da Caatinga são endêmicas. Esse número também inclui a ocorrência de 29 gêneros endêmicos, que tendem a possuir distribuição muito restrita e ser localmente raros”. (Ciência e Cultura) 
Diante desta abordagem, é indispensável conscientizar o sertanejo sobre a importância desse tipo de vegetação, que é própria do semiárido nordestino e que fornece materiais como a lenha, o carvão e também muitos outros produtos que não se relacionam somente ao seu potencial madeireiro, como frutas, mel, sementes e algumas outras plantas medicinais, inclusive muitas plantas que servem de alimento para os animais de criação.

Visto que houve um aumento significativo no desmatamento da caatinga nos últimos anos, surge a preocupação de manter e preservar este patrimônio natural.

Tabela 3915 - Áreas total, remanescentes e desmatadas, até 2009, da Caatinga, e respectivos percentuais, para as Unidades da Federaçäo abrangidas pelo inventário

\begin{tabular}{|l|r|}
\multicolumn{2}{|c|}{ Variável - Percentual da área da Caatinga desmatada até 2009 $(\%)$} \\
\hline \multicolumn{1}{|c|}{ Total e Unidade da Federação } & \\
\hline Total & 46,6 \\
\hline Maranhäo & 30,7 \\
\hline Piaui & 30,9 \\
\hline Ceará & 40,4 \\
\hline Rio Grande do Norte & \\
\hline Paraíba & 46,9 \\
\hline Pernambuco & 46,4 \\
\hline Alagoas & 54,9 \\
\hline Sergipe & 82,6 \\
\hline Bahia & 68,5 \\
\hline Minas Gerais & 53,3 \\
\hline
\end{tabular}

Fonte: Relatório técnico - Monitoramento do desmatamento nos biomas brasileiros por satélite - Acordo de Cooperação Técnica MMA/lbama: Monitoramento do Bioma Caatinga 2008-2009.

Disponivel em <http://www.mma.gov.br/estruturas/sbf_chm_rbbio/_arquivos/relatorio_tecnico_caatinga_2008_2009_72.pdf>Acesso em jan. 2015

A caatinga, que na língua indígena significa Mata Branca, é um bioma extremamente frágil, que sofre forte pressão do desmatamento, segundo o relatório de monitoramento do desmatamento da caatinga do Ministério do Meio Ambiente de 2011 , até o ano de 2009 já foram suprimidas 45,62\% da vegetação da caatinga e isso tem levado o bioma ao longo dos anos a um rápido processo de desertificação.”(PEREIRA, 20II)Figura I, Fonte: Relatório técnico- Monitoramento do desmatamento brasileiro. MMA/Ibama- 2008-2009

Ao analisarmos a figura I, é notável como a área da caatinga vem sendo desmatada de forma acelerada até o ano de 2009. Atualmente, cerca de $46 \%$ do seu território tem sido 
explorado de forma ilegal. É necessário que se tenha um primeiro passo diante desta circunstância, e um destes primeiro passo sugerido é exatamente ensinar. Sabendo do poder que a educação exerce na vida das pessoas, destacamos como primeiro passo a ser dado a difusão de palestras e seminários educativos voltados para as questões do bioma caatinga, nesse contexto quem se responsabilizaria seria majoritariamente o governo municipal, por estar mais próximo dessa população e conhecer sua realidade, os demais governos estadual e federal auxiliando por meio de fomentos, criando cooperativas que continuem a preservar os conhecimentos adquiridos além de incentivar uma massa de produtores com um bem comum.

E para que se tenha essa educação é necessário primeiramente fazer com que os mesmos venham compreender sobre o que é o manejo sustentável de recursos florestais, isto porque, o manejo florestal é um dos principais pilares para a preservação da caatinga, sendo de grande importância para redução dos impactos causados pelo homem, visto que a fauna e flora deste bioma são importantes, e de grande predominância no nordeste brasileiro.

Um dos maiores desafios para a conservação das florestas, é o manejo sustentável dos recursos, porém, é de total importância que se faça esse manejo o mais rápido possível, isto porque, existe uma grande possibilidade deste bioma acabar sendo desertificado, caso seu uso não seja feito de maneira legal, sendo explorada de maneira planejada, e com a preservação dessa fauna e flora, não afetando a sua biodiversidade.

Para isto, é necessário primeiramente que a população se conscientize e que os governantes façam projetos para sua preservação, que as escolas trabalhem questões ambientais, principalmente sobre este bioma endêmico do Brasil.

Que seja elaborado um plano de manejo florestal, sendo utilizado de maneira sustentável, buscando sempre o mínimo de danos ambientais e os maiores benefícios para a floresta e para todos aqueles que dependem desse bioma, que sejam aplicadas técnicas de manejo florestal para redução dos impactos da exploração, e degradação desse bioma, e que se tenha leis que garantam a sustentabilidade florestal dos recursos nativos da caatinga, com o planejamento e monitoramento desse bioma, que visem seu crescimento, e desenvolvimento de suas espécies nativas.

\section{CONCLUSÃO}


Este trabalho buscou através de pesquisas bibliográficas entender a relação do extrativismo dos recursos naturais da caatinga, a monocultura extensiva, a caça predatória, etc.. com o desenvolvimento e sustentabilidade, entretanto se não houver o manejo adequado e sustentável ocorrerá a desertificação e extinção de espécies em grandes áreas como já tem mostrado os dados do INPE que aproximadamente 40\% da Caatinga está degradada, 8\% do solo está exposto e propenso a desertificação, 8\% é utilizado para o cultivo e somente $42 \%$ está preservada, sendo o bioma que menos tem áreas preservadas.

É necessário o monitoramento e aplicação de normas e leis que contemplem o manejo adequado com o desenvolvimento e sustentabilidade, pois a caatinga ainda é fonte de recursos e matéria prima para indústrias, fábricas que ainda utilizam como fonte de energia a biomassa. Os agricultores familiares e a população devem ser conscientizados através de medidas educacionais de manejo correto e publicidades que mostram as consequências que a degradação da caatinga pode causar.

Assim, o manejo sustentável tem como base a administração da floresta para obtenção de recursos para sua própria preservação, e para população que depende da mesma, respeitando os mecanismos de sustentação do ecossistema, e a preservação ambiental de suas espécies, visando o crescimento sustentável da caatinga, e produzindo bens e serviços florestais que possam ser explorados de maneira legal, reduzindo os impactos ambientais na caatinga, trazendo preservação e evolução para o bioma, evitando a desertificação e extinção de suas espécies .

\section{REFERÊNCIAS}

Ciência

e

Cultura.

Disponível

emhttp://cienciaecultura.bvs.br/scielo.php?script=sci_arttext\&pid=Sooog-

67252018000400014> acesso em: I4 de maio de 2021.

GIL, Antônio Carlos. Métodos e técnicas de pesquisa social. São Paulo: Atlas, 1987. ISBN $85-224-0489-5$.

GARRIDO FILHA, Irene. Manejo florestal: questões econômico-financeiras e ambientais. Estud. av., São Paulo, v. I6, n. 45, p. 91-106, Aug. 2002. Available from $\langle$ http://www.scielo.br/scielo.php?script=sci_arttext\&pid=Soro3-

40142002000200007\&lng=en\&nrm=iso $>$ access on 15 May 2021. http://dx.doi.org/10.1590/So103-40142002000200007.

GOMES, J. S. et al. Geração de renda e o manejo florestal em assentamentos de Pernambuco. Revista de Política Agrícola. Ano XXII - N. 4. p.56-66. Out./Nov./Dez. 2013. 
IBGE - INSTITUTO BRASILEIRO DE GEOGRAFIA E ESTATÍSTICA. Território. Rio de Janeiro: IBGE, 2004. Disponível em: >https://brasilemsintese.ibge.gov.br/territorio.html<. Acesso em: I6. Maio. 202I.

INSTITUTO NACIONAL DE PESQUISAS ESPACIAIS (INPE). INPE Nordeste mapeia desmatamento da Caatinga, 2015. disponível em: $\langle$ http://www.inpe.br/noticias/noticia.php?Cod_Noticia=3895>. Acesso em: 09. Maio.2021.

INSTITUTO NACIONAL DE PESQUISAS ESPACIAIS (INPE). Centro do INPE avança no mapeamento da Caatinga, 2or6. Disponível em: $\langle$ http://www.inpe.br/noticias/noticia.php?Cod_Noticia=4157>. Acesso em: 09. Maio.202I.

MARCONI, Marina de Andrade; LAKATOS, Eva Maria. Fundamentos de Metodologia Científica. 5. ed. São Paulo: Atlas, 2003. ISBN 85-224-3397-6.

MATA NATIVA, O que é manejo florestal? Mata Nativa, 2019. Disponível em: <https://www.matanativa.com.br/manejo-florestal-sustentavel/> acesso em: is Maio 202I

Ministério do meio ambiente - MMA. Disponível em: https://www.mma.gov.br/biomas/caatinga acesso em: I4 de maio 202I

NETO, Pedro N. de M. OLIVEIRA, Elisabeth. PAES, Juarez B. Relações entre as características da madeira e do carvão vegetal de duas espécies da caatinga. Floresta Ambiental. vol. 2i n.4 Out/Dez-20I4.p.i-ro.

PEREIRA, Magnum de Sousa. Manual técnico Conhecendo e produzindo sementes e mudas da caatinga. Fortaleza: Associação Caatinga, 20II. 6o p. il.

RIEGELHAUPT, Enrique M. PAREYN, Frans Germain C. GARIGLIO, Maria A. O Manejo Florestal como ferramenta para o uso sustentável e conservação da Caatinga. In: Uso sustentável e conservação dos recursos florestais da Caatinga. Serviço Florestal Brasileira, Brasília- 20ı. p.349-367. 